\title{
CORTISONE AND ANAESTHESIA
}

\section{A G. F Romagnoli, M.D *}

IN 1855 Dr Thomas Addison published a monograph entitled "The Constitutional and Local Effect of Disease of the Suprarenal Capsules." This is the first study of great value in the history of endocrinology of the Adrenal Glands. He stated that these glands are essential for the maintenance of life.

In 1856 Brown-Séquard performed the first experimental adrenalectomy to confirm the statements of Addison. But it was not untll 1930 that we were sure of the hypophyseal control of the adrenals and we began, to extract biologically active substances from these glands

Only a few years ago science was successful in isolating Cortisone and A.C.T.H. An average of nearly two thousand papers have since been sublished every year on these hormones. It is easy to imagme how chaotic and contrasting are many of their findings.

A C TH. is a polypeptide and its formation may be influenced by the diet: high carbohydrate and low protein intake may decrease the output, severe denutrition produces a syndrome in many ways similar to hypophysectomy. This hormone is secreted by the basophil cells in the pituitary gland and the secretion seems to be regulated both by nervous impulses from the hypothalamus and by chemical substances reaching the gland through the hypophyseal portal system of blood vessels from the hypothalamus to the anterior lobe. The amount of cortical hormone in the crrculation also influences the production Besides there is a theory, now dened by some authors, that postulates adrenalin and noradrenalin as important factors in the stumulation of A.C.T.H. output

Cortisone (11-dehydro-17-hydroxycorticosterone) is released by the adrenal cortex and A C T.H is the most important stımulus M Saffran and coworkers (1) found that homogenated hypothalmic tissue stimulates isolated adrenals only after adding adrenalin or noradrenalin. These two compounds alone have no action on the solated adrenals. A substance extracted from an impure vasopressin preparation has the same potency as the one found in the hypothalamic tissue. It strongly stımulates the isolated adrenals in presence of adrenalin and noradrenalin The chemical structure is stll unknown, but there is evidence to believe that it is a peptide. In addition the level of circulating cortisone regulates the cells of the adrenal cortex in the formation of the hormone itself. Other endocrine glands may be responsible too.

The interrelationship of the pituitary-adrenal system and other endocrine systems is so wide and complicated and still so much in the dark that it is beyond the scope of thes paper to go into it.

In brief I shall now enumerate the actions that the A.C.T.H -Cortisone combination seems to have on the organism. In this I shall follow Professor Li

"From the Department of Anaesthesı, McGill University, Montreal. 
(1950) (2), Sprague (3), Power and Mason (1950), Suzman (1953) (4), and other authors $(24,25)$.

1. Retardation of body growth and antagonism to the action of the growth hormone. This demands the careful adjustment of dosage in infants and children.

2. Increase in nitrogen and potassium excretion. Signs of hypopotassaemia may occur, such as apathy, lethargy, muscular weakness, cramps, abdominal pain, and distension. This complication can be corrected or controlled by the $\mathrm{ad}_{r}$ ministration of adequate amounts of $\mathrm{KCl}$.

3. Increase of the free aminoacid content of the plasma.

4. Glycosuria and hyperglycaemia. This can be disregarded unless the patient is diabetic, in which case extra insulin must be given.

5 . Increase of body fats.

6. Hypertrophy of the liver with increased hepatic blood flow and increased liver fats. Aterman (1953) (5) showed that in rats Cortısone decreases the liver resistance to toxic substances, such as $\mathrm{CCl}_{4}$.

7. Increase of Ketone bodies in urine and blood.

8. Diminution of the plasma alkaline-phosphatase.

9. Deterioration in chondrogenesis and osteogenesıs of the tibia. Tissue wasting and osteoporosis are more apt to occur in elderly patients, in whom spontaneous fractures have been reported. To prevent or control these complications high protein diet, calcium, and anabolic agents, such as androgens and estrogens, should be administered.

10. Thinning of the epidermis and atrophy of the sebacious glands and the growing parts of the hair.

11. Corticogenic hypothyroıdısm. Thıs syndrome can develop only with prolonged administration, but the complication is of the greatest importance, because lack of thyroid hormone diminishes the responsiveness of the adrenal cortex to A.C.T.H. and of the tissues to Cortsone, with the result that the administration may become ineffective.

12. Involution of the thymus and lymph-nodes with depletion and involution of lymphocytes.

13. Decrease in circulating eosinophls, but increase in the production of neutrophils and erythrocytes.

14. Enhancement of work performance, because of augmentation of muscular power.

15. Improved resistance in normal rats to cold, starvation, and low atmospheric pressure.

16 Increased capillary resistance

17. Inhibition of the insulin effect on 1solated diaphragm of normal rats, but not of hypophysectomized animals.

18. Inhibition of male accessories of normal rats, but not of hypophysectomized animals.

19. Early retention of $\mathrm{NaCl}$ and $\mathrm{H}_{2} \mathrm{O}$, followed by increased excretion while the hormone is still being administered. This early retention may be very harmful for certain patients, such as those affected by heart diseases or hypertension, and during pregnancy. However, this complication can be controlled by decreasing the $\mathrm{NaCl}$ intake and by prescribing substantial amounts of $\mathrm{KCl}$, which tends to 
limit the retention of $\mathrm{NaCl}$ and $\mathrm{H}_{2} \mathrm{O}$, mercurial diuretics and cation exchange resins may also be of value.

20. A.C.T.H. stimulates the adrenal cortex output of steroids. Morphologically there is hypertrophy and hyperplasia, involving mainly the zona fasciculata and the zona reticularis, with narrowing of the zona glomerulosa. The secretory activity is increased and there is depletion of cell lipids.

21. Cortisone produces exactly the reverse of effects seen in unilateral hyperfunctioning cortical tumours. The evidence for this statement is: $(a)$ postcortisone asthenı, $(b)$ depression of urinary '17-ketosteroids during and after adminıstratıon, (c) diminushed response to A C T.H. (Thorn's Test), (d) atrophy of various degrees of the adrenal cortex observed at necropsy.

22. A.C.T.H. and Cortisone have been seen to produce some androgenic changes in chıldren and young women, such as acne, hirsutism, moonlike face, buffalo hump, atrophic striae and thinning of the scalp hair, which have immediately regressed when the administration of the drug was stopped.

23. Menstrual function is usually stopped, especially in young girls.

24 A wide variety of psychic effects has been reported by many. Mild degrees of stmulation and euphoria are fairly frequent. Manrac behaviour, depression, and frankly psychotic states are indeed more rare. Severe reactions are more likely to occur in persons with a background of nervous instability.

25 A.C.T.H. and adrenocortical steroids, by this complex and wide variety of actions, have a great influence on the defence mechanisms of the body against stress. In this sense they constute a basic factor in the general adaptation syndrome and the stress theory of disease propounded by Selye (23). They increase the defence mechanism of the host rather than attack the pathogen, irrespective of its nature. It is therefore understandable that we may now meet with success even when the cause of the disease is unknown. They are natural biological products and, although therr influence on the body is often very profound, therr action is nevertheless physiological in type as they produce ar exaggeration or a dimunution of normal metabolic processes. Thus no lll effect of permanent nature has ever been observed in patients who have received these hormones continuously for long periods. Most of the side effects' and complications have occurred only durmg high dosage admmistration, and in children and young adults.

26. Winter and Flataker (1953) (6) found that in animals under the effect of morphine, cortisone has a definite central stimulating action influencing the entire cerebrospinal axis.

27. The oxygen consumption in granulation tissue is 66 per cent decreased by Cortisone.

28. Abrams and Harris (1951) (7) found that in rabbits treated with Cortisone there was a marked and immediate increase in the amplitude of the QRS deflections and T-waves. However, Chapman (26) and coworkers demonstrated in dogs that this hormone had no deleterious effects on the infarction areas, and the healing process was not at all impaired.

29. Kenyon (1947) (8) has pointed out that certain signs and symptoms of adrenal tumours have been reproduced to some extent by the administration of pure steroids: (a) hypertension by Desoxycorticosterone Acetate; (b) $\mathrm{Na}^{+}$and 
$\mathrm{H}_{2} \mathrm{O}$ retention by Desoxycorticosterone Acetate and Cortiscine; (c) diabetes and $\mathrm{N}_{2}$ loss by Cortisone, $(d) \mathrm{N}_{2}$ gain and somatic growth by testosterone (one should also keep in mind the work of Kinsell (1952) (9) who reported that the catabolic effects of Cortisone on protems are neutralızed by testosterone), (e) masculinization and femmization with depression of gonadal function by androgens and estrogens respectively; $(f)$ atrophy of the adrenal cortex by Cortisone.

\section{Cortisone and Anaesthesia}

I shall only examine those situations in which Cortusone directly concerns the anaesthetsst, and this is around the date of an operation. He will find it indicated:

(1) To prepare the patient for an operation treating conditions not directly involving the adrenal cortex, (2) To prevent shock and speed recovery, (3) To prepare the patient for adrenocortical surgery.

1. Cortisone ameliorates bronchial asthma as proved now by many workers Therefore it can be administered for this purpose to severely affected patients pre-operatively The mechanism of action seems to be due to the antihyaluronidase effect. But it must be remembered that it has been found that rheumatord arthritic patients have a consistent decrease in functional residual capacity of the lung, paralleling the increase in skeletal mobility.

MacGougan and Thorson (1952) (10) found A C T.H. very useful in relieving oedema and bronchial hypersecretion, before bronchoscopy for the removal of foreign bodies.

Margulis (11) in 1951 and Flessman (12) in 1953 reported cases of posttraumatic anuria which responded dramatically to A.C.T.H and Cortisone. The mechanism of action is obscure, but seems to be the result of the fact that these hormones are able to relieve the post-traumatic ischemia of the kidney

Horwitz (1953) (13) used Cortisone very successfully to relieve the severe bronchospasm in a bad case of bronchiectasis in order to perform a lobectomy

Suzman (1953) (4) administered A C T H to three patents in severe shock caused by pulmonary embol, who were not responding at all to ant-coagulant therapy. Prompt and dramatic improvement ensued and recovery occurred. The fourth patient improved, but died later.

Lurie (1953) (14) treated a man in barbiturate coma with $20 \mathrm{mg}$ of Cortisone and Vitamm $B_{12}$ in $1,000 \mathrm{cc}$ of normal saline with return of consciousness in a few hours. However Gorby (1953) (22) showed that the protective effect of Cortisone against pentobarbital $\mathrm{LD}_{50}$ is minimal.

2. Cortisone ( $\mathrm{Ll}, 1950(2)$ ) by its complex mechanism of action increases the resistance to stress stımul, if adminıstered preoperatively, but Modern (1951) (15) advises caution and even says that patients on Cortisone should be taken off, because it may delay healing owing to the tissue-repair inhibiting effect However, it is now generally agreed that moderate doses do not impair healing or body resistance to infection, and that patients on Cortisone therapy can safely undergo surgery as long as the dosage is increased for a few days around the time of the operation.

Very debilitated, cachectic, and senile patients and those who have suffered severe and prolonged stress would have the Thorn's Test, the Epinephrine- 
Eosinophil Test, and the Eosinophil count done to assess as much as possible the Adenohypophysal-Adrenocortical Reserves. Hayes and Coller (17), Kelso and Keaty (18), and many others fully support this view and state that almost miraculous results can be achieved with the administration of small amounts of Cortisone before and after operation, according to the case.

Patients who have had Cortisone for any length of time must be presumed to have some atrophy of the adrenal cortex, which may produce varying degrees of cortical insufficiency when under stress such as surgery, fever, and anaesthesia (Sprague (3), Power and Mason 1950, Paulshock 1954 (19)). Sudden and dangerous hypotension may develof and may not respond to palliative treatment. Cortisone is the specific remedy, if given in time, and there is no better time than before the crisis develops.

3. Walters and Kepler (20) say that the most important factor in surgical therapy is the anticipation, prevention, and control of postoperative adrenocortical insufficiency.

Now that Cortisone and Desoxycorticosterone Acetate (DOCA) are available in pure form and patients without adrenal glands can be kept in good health for long periods, it is our duty to see that adrenal crises are prevented.

Until the last decade the mortality from the estirpation of hyperfunctioning adrenal tumours was very high and Cecil (21) reports 33 per cent deaths. An

TABLE I

Substitution Therapy for Total AdRenalectomy

(Huggins and Bergenstal 1951 (16))

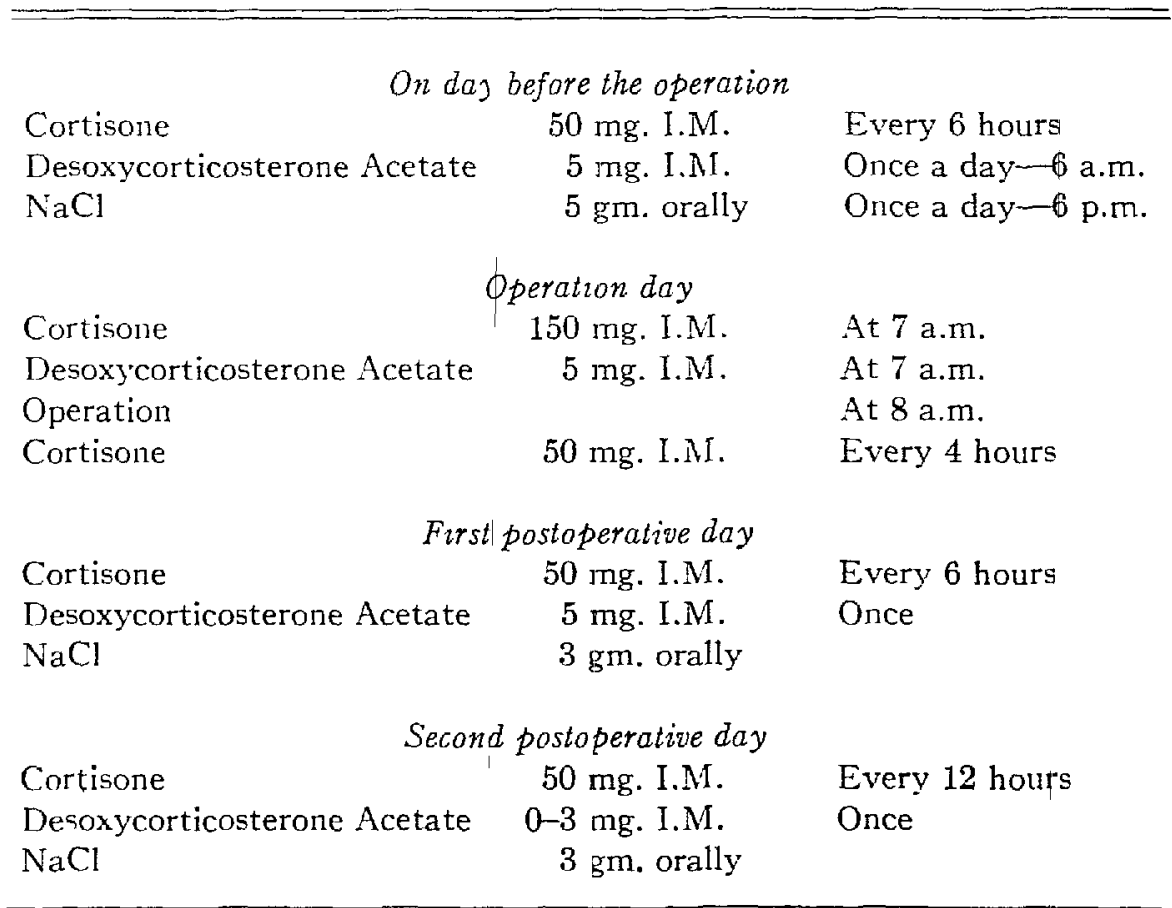

During the subsequent days the dose of steroids is gradually reduced until the sustaining dose of Cortisone is reached (25-50 mg. daily) about one week after the operation. Desoxycorticosterone Acetate is usually not required for maintenance therapy. 
important finding, in patients who died for the removal of an adrenal tumour, was that the controlateral adrenal gland could not be found at autopsy.

Adrenocortical insufficiency is rarely cured once it has developed immediately after an operation, especially if it is at all severe. The rule must be to treat the patient in advance as if the insufficiency were certain to develop postoperatively, and to withdraw the essential medicines slowly in the days following the operation. Therefore the well-timed administration of adequate doses of Cortisone and Desoxycorticosterone Acetate is most important. (See Table I.)

Blood loss must be replaced by transfusion during and after the operation, if necessary. The systolic blood pressure must be maintained above $100 \mathrm{~mm}$. $\mathrm{Hg}$. using continuous infusion of Noradrenalin $10 \mathrm{y} / \mathrm{cc}$. of N.S S. if required. The total amount of the fluid injected during the first postoperative day should not exceed $1,500 \mathrm{cc}$. If the temperature rises above $38^{\circ} \mathrm{C} ., 0.6 \mathrm{gm}$. of Acetylsalicylic acid is given orally. The maintenance dose of Cortssone $25-50 \mathrm{mg}$. daily is usually started on the sixth postoperative day. The patent supplements his diet by ingesting $2-4 \mathrm{gm}$. of $\mathrm{NaCl}$ daily.

\section{CONCLUSION}

Today Cortısone permits the surgeon and the anaesthetsst to perform operations to cure diseases which only a few years ago were extremely dangerous The surgical approach may then have been worse than the disease itself to the patient, and very discouraging indeed to the surgical team Now adrenal surgery can safely be performed and the anaesthetist has at hand a drug that allows hum to bring through an operation many patients whose general conditon might, before, have been an absolute contraindication to surgery and anciesthesia Nevertheless, we must not forget that many other problems have been created by Cortsone, because there is no tissue or system in the body which is not influenced in its metabolism by the A C.T H -Cortisone combination. Up to date we have only a fragmentary knowledge of its mode of action, and I beheve that this should be a stimulus to use the greatest caution, both in its clinical application and in the interpretation of its effects.

\section{SUMMARY}

Cortisone and A C TH act on every tissue of the organism by a mechanism which is still unknown; therefore, they must be used with extreme care The cases must be meticulously selected and the dose must be adjusted for each case so that it will bring about the best result with the least side effects. The evaluation of these results is also difficult.

On the whole, we feel that it is better to use A.C T H. than Cortisone, because in this way at least the post-cortsone hypotrophia and hypoplasia of the adrenal glands, so dangerous to "stress," can be completely avoided

The treatment for patients undergoing adrenal surgery is outlmed

\section{RÉSUMÉ}

La Cortisone et l'A.C.T.H. agissent sur tous les tissus de l'organisme par un mécanisme encore inconnu. G'est pourquoi, on doit les employer qu'avec très 
grandes précautions. Les cas doivent être choisis de façon méticuleuse et la dose doit être ajustée pour chaque cas de tel sorte qu'elle produise le meilleur résultat possible avec le moins d'effets secondaires. L'évaluation des résultats est aussi difficile.

A tout considérer, nous croyons qu'il vaut mieux employer l'A.C.T.H. que la Cortisone parce que de cette façon au moins, on évite les effets d'hypotrophie et d'hypoplasie des surrénales sl dangereuses sous le "stress."

On donne le traitement à suivre chez les patients qui doivent avoir une intervention sur les surrénales.

\section{REFERENCES}

1. SAfFran, $M$ et al Production of Corticosteroids by Rat Adrenals in vitro Endocrnology 50639 (1952).

Schally, A V. Endocrinology (in piess 1955)

Schally, A V and Benfey, B G Role of the Neurohypophysis in the Release of A C.T H Meeting of the Amencan Endocrine Society, Atlantuc C1:y, June, 1955. Personal Communcation

2 LI, C H. Action of A C.T H Lancet 1. 213 (1950)

3. Sprague, R G et al The Physiological Effects of Cortusone and A CT.H in Man J A M A 1441341 (1950)

4 Suzman, M. M. Clinical Application of Corticotropin and Cortisone Therapy South African Med J 27. 195 (1953)

5 Aterman, K and Ahmad, N. D Cortisone and Liver Function Lancet 1(2): 71 (1953).

6 Winter, C A and Flataker, L. Effects of Cortisone, Desoxycorticos :erone, Ashenscorticotropic Hormone and Diphenhydramine upon the Response of Albiro Mice to General Anaesthetics J Pharmacol \& Exper Ther 105. 358 (1952)

7 Abrams, $W B$ and Harris, $T N$ Effects of Cortisone on E C G $\sigma^{2}$ Normal Rabbits Am. Heart J 42875 (1951).

8 KenYon, A T Adrenal Cortucal Tumors. Physiologic Considerations, in Endocrinology of Neoplastic Diseases Twombly and Pack, editors. New York Oxford University Press (1947)

9 Kinsell, L W et al Dietary Modifications of Metabolism and Clinical Effects of A C T.H. and Cortisone Ann Int Med 37921 ( 1952 )

10 MacGougan, M. K. and Thorson, S B A C TH in Aspiration of Peanuts C M A J 66 $371(1952)$

11 Margulis, $R$ R in Mote, J. R Second Clinical A C.T H Conference London: Churchill Limited (1951)

12 Fleishman, S J Prompt Reversal of the Post-Traumatic Oliguric Syncrome by A C T.H and Cortisone South African Med J 27. 234 (1953)

13 Honwitz, $M$ Bronchial Asthma, Rheumatoid Arthritis and Connective Tissue Diseases Treatment with Cortisone and ACTH South African Med J 27213 (1953)

14. LuRIE, M. B. Treatment of Barbiturate Polsoning with A C T H. Acta Med Or (Jerusalem) 1287 (1953)

15 Modern, F W ACT.H. and Cortisone in Surgery Ann West. Med \& Surg 5153 (1951)

16. Huggins, C and Bergenstal, D. M. Surgery of the Adrenals J A M A 147. 101 (1951)

17 Hayes, M. A. and Collen, F. A. Neuroendocrine Control of Water and Electrolyte Excretion during Surgical Anaesthesia. Surg, Gynec \& Obst $95 \quad 142$ :1952)

18 Kelso, W. and KeAtY, C. Postoperative Use of Cortisone Surg Gynec. \& Obst 92295 (1951)

19 Paulshock, B Z. Surgically Precipitated Adrenal Cortical Insufficiency in a Patient Previously Receiving Cortisone Delaware State M. J 2515 (1954) 
20. Waxters, W and Kepler, E. J. Surgical Lesions of the Adrenal Glands J A M A 111 1051 (1938).

21. CecIL, H L. Hypertension, Obesity, Virllism and Pseudohermaphroditism as caused by Suprarenal Tumors J A M A 100463 (1933)

22 Gorby, C K. et al The Effects of Cortisone and Desoxycorticosterone on the Toxicity of Barbiturates J Am Pharm A. (Scient Ed) 42213 (1953)

23. Selye, H. A Syndrome Produced by Diverse Noxious Agents. Nature (London) 138. 32 (1935)

- The General Adaptation Syndrome and the Diseases of Adaptation J. Clin. Endo${ }_{2}$ crinol. 5. 117 (1945)

24. Moone, F D and Ball, M R The Metabolic Response to Surgery. Ist ed., Springfield, Illinors. Thomas (1952).

25 Drull, V A Pharmacology in Medicine 1st ed., New York. McGraw-Hull Book Company, Inc (1954)

26 Chapman, D W et al Effects of Cortisone in Experimental Myocardial Infarction. Am. J Med Scien 22341 (1952). 